\title{
Research on Township Medical Service Institutions Spatial Coping Capacity of Extreme Climate Disasters in Severe Cold Regions
}

\author{
Bai Xiaopeng ${ }^{1,2}$, Yu Zhenfan ${ }^{1}$ \\ ${ }^{1}$ Architectural Design and Theory, Harbin Institute of Technology, Harbin, China \\ ${ }^{2}$ Architecture, Harbin Institute of Technology, Harbin, China \\ Email address: \\ 371691189@qq.com (Bai Xiaopeng),yzf371691189@163.com (Yu Zhenfan)
}

To cite this article:

Bai Xiaopeng, Yu Zhenfan. Research on Township Medical Service Institutions Spatial Coping Capacity of Extreme Climate Disasters in Severe Cold Regions. Science Discovery. Vol. 6, No. 2, 2018, pp. 130-136. doi: 10.11648/j.sd.20180602.19

Received: April 19, 2018; Accepted: May 7, 2018; Published: June 22, 2018

\begin{abstract}
Extreme Climate Disasters represented by extreme cold weather, snowstorms and gales are the most important factors which restrict the development of Township Medical Service Institutions and threaten health security of townspeople in severe cold regions. Through deep investigation and research on Medical Service Institutions of Villages facing Extreme Climate Disasters, this paper finds out its weakness on architectural operation system and inner space. In order to solve existing problems, we put forward some measures from the view of architecture, such as space function transformation and space modularization. As a result, we provide new solutions for Township Medical Service Institutions whose development is seriously impeded by Extreme Climate Disasters.
\end{abstract}

Keywords: Extreme Climate Disasters, Township Medical Service Institutions, Severe Cold Regions, Architectural Space

\section{应对极端气候灾害的寒地乡镇医疗机构空间保障能力研究}

\section{白小鹏 ${ }^{1,2}$, 余振凡 ${ }^{1}$}

${ }^{1}$ 建筑学院建筑设计及其理论专业, 哈尔滨工业大学, 哈尔滨, 中国

2建筑学院建筑学专业, 哈尔滨工业大学, 哈尔滨, 中国

邮箱

371691189@qq.com（白小鹏）,yzf371691189@163.com（余振凡）

摘要：以低温冷冻、雪灾和大风为代表的极端气候灾害是制约寒地乡镇医疗机构发展、威胁乡镇居民公共健康安全的 重要因素。通过对中国寒地乡镇医疗机构应对极端气候灾害现状的调研, 寻找寒地乡镇医疗机构在建筑运作体系、建 筑内部空间等方面应灾医疗服务的不足。本研究从建筑空间布局的角度寻找弥补的措施, 提出寒地乡镇医疗机构的建 筑应灾体系设计、空间功能转化对策、空间模块化设计对策。从而为提高寒地乡镇医疗机构的应灾能力找到新的途径。

关键词：极端气候灾害，乡镇医疗机构，严寒地区，建筑空间 


\section{1. 引言}

全面提升乡镇医疗机构的服务能力和水平是中国国 务院办公厅《全国医疗卫生服务体系规划纲要 (2015-2020 年)》文件的重要内容, 是全面深化中国医药体制改革的 重要内容[1]。而中国的高纬度严寒地区面积接近全国土地 面积的三分之一，这些区域低温冷冻、雪灾和大风等极端 气候灾害频发，对该地域人民的生命和财产安全造成了严 重的威胁, 且对当地乡镇医疗机构的卫生服务能力提出了 挑战, 而应对极端气候灾害的空间保障能力直接影响甚至 决定了上述能力存续与提升。因此, 为了贯彻《“十三五” 平安中国建设规划》文件的核心精神、为了切实的保障乡 镇居民的健康和安全, 找到乡镇医疗机构的应灾薄弱点、 加强相关机构的应灾空间保障能力就显得尤为关键。

\section{2. 研究背景}

随着新医改的进行和“十三五”全面深化医疗体制改 革的提出, 中国寒地乡镇医疗机构得到了国家和社会越来 越多的关注和支持, 发展迅猛[2]。寒地乡镇医疗机构的规 模和功能日趋扩大和完善。可是由于缺乏合理的应灾设计, 当以低温冷冻、雪灾和大风为代表的极端气候灾害来临时, 寒地乡镇医疗机构的建筑空间往往既无法保证自身建筑
安全、提供正常的医疗服务, 亦无法满足灾时和灾后激增 的就医需求。

本研究在地理区位上界定在严寒地区, 主要的研究对 象是乡镇医疗机构建筑, 强调了寒地乡镇医疗机构目前较 为薄弱的应灾侧面, 旨在将寒地乡镇医疗机构的建设思路 提升到另一个层次, 在理论层面上为严寒地区基层医疗机 构的设计提供了新的应灾思路, 从而满足防灾减灾的新要 求，保障基层人民的公共健康与安全。

\section{1. 极端气候灾害发生的高频率和高破坏性}

根据IPCC（International Panel on Climate Change）第 四次评估报告的具体内容, 自 20 世纪70年代以来，在全球 范围内, 已观测到的极端气候所带来的灾害正在蔓延, 全 球范围内极端气候事件以及其导致的衍生灾害事件频发, 造成了巨大的经济损失和人员伤亡[3]。根据中国民政部国 家减灾办发布的2016年全国自然灾害基本情况可知: 2016 年度各类自然灾害共造成近 1.9 亿人次受灾，直接经济损 失高达 5032.9 亿元, 因灾死亡人数和因灾失踪人数相比 2015年度升高约70\%。而黑龙江省作为严寒地区的代表区 域, 2016年遭受冰雨、洪涝、雪灾等灾害影响的人数高达 25 万人 [4]。另一方面, 极端气候灾害容易引起居民（尤其 是幼儿、老人等脆弱群体) 的呼吸系统疾病、心血管系统 疾病以及摔伤、骨折等外科伤病, 造成灾时和灾后就医需 求激增的现象。

表1 2017-2018年度部分寒地极端气候灾害事件统计表。

\begin{tabular}{ll}
\hline 时间 & 极端气候灾害事件描述 \\
\hline 2018年1月22日 & 辽宁省遭受寒流侵袭, 最低气温可达-39 ${ }^{\circ} \mathrm{C}$, 创该地区十六年来最低气温。 \\
2017年7月20日 & 黑龙江省尚志市遭受暴雨侵袭, 造成直接经济损失2292.6万元, 近万人受灾。 \\
2017年5月31日 & 东北地区遭受因寒流导致的冰雹灾害影响, 黑龙江、吉林、辽宁三省共计近三万余人受灾, 直接经济损失达4700万元。 \\
2017年2月15日 & 内蒙古阿尔山市遭受暴雪侵袭, 风力达到6级以上, 能见度不足10米, 积雪厚度最高可达20厘米。 \\
\hline
\end{tabular}

\section{2. 寒地乡镇医疗机构空间的应灾保障能力缺失}

目前中国乡镇的 “三级医疗卫生服务体系” 已日趋完 善, 县医院、乡镇卫生院、村卫生室三级医疗机构相辅相 成, 基本满足了乡镇居民的日常就医需求; 另一方面, 中 国大部分地区, 尤其是城市区域, 都已经实现了应灾医疗 保障空间的区域人群覆盖。但是由于长期以来，中国对基 层医疗卫生服务系统投入的不足以及 “重城市、轻农村” 的发展思路, 导致寒地乡镇医疗机构空间的应灾保障能力 缺失。

寒地乡镇医疗机构空间的应灾保障能力缺失具体表 现在建筑空间无法在极端气候灾害中保证自身的建筑安 全; 以及建筑空间无法有效的应对由极端气候灾害引起的 呼吸系统疾病、心血管系统疾病、外科伤病等激增的病情
[5]。鉴于中国总人口数的 $49.73 \%$ 为乡镇人口, 因此解决中 国乡镇居民的灾时与灾后的医疗问题是中国公共医疗卫 生事业的重要任务[6]。

\section{3. 寒地乡镇医疗机构应灾空间保障能力现状}

笔者跟随研究团队深入中国黑龙江省的基层, 在保证 调研结果的多样性、均衡性、可操作性以及代表性原则的 前提下, 走访了十三个具有代表性的寒地乡镇医疗机构, 样本共计覆盖了311299（人）的寒地乡镇医疗服务人口。 通过对这十二家乡镇医疗机构的调查研究, 找出了中国寒 地乡镇医疗机构在运作体系、建筑内部空间等方面应灾医 疗服务的不足。

表2 寒地乡镇医疗机构概况统计表。

\begin{tabular}{llllll}
\hline \multirow{2}{*}{ 序号 } & 寒地乡镇医疗机构概况 & & & \\
\cline { 2 - 5 } & 名称 & 地理位置 & 建造年份 & 服务人口 & 建筑面积 \\
\hline 1 & 红旗镇卫生院 & 七台河市红旗镇 & 2005 & 22000 人 & $3000 \mathrm{~m}^{2}$ \\
2 & 长兴乡卫生院 & 七台河市长兴乡 & 2001 & 19000 人 & $2150 \mathrm{~m}^{2}$ \\
\hline
\end{tabular}




\begin{tabular}{|c|c|c|c|c|c|}
\hline \multirow{2}{*}{ 序号 } & \multicolumn{5}{|c|}{ 寒地乡镇医疗机构概况 } \\
\hline & 名称 & 地理位置 & 建造年份 & 服务人口 & 建筑面积 \\
\hline 3 & 榆树镇卫生院 & 哈尔滨市榆树镇 & 2002 & 22000 人 & $2750 \mathrm{~m}^{2}$ \\
\hline 4 & 红旗满族乡卫生院 & 哈尔滨市红旗满族乡 & 2014 & 23125人 & $4200 \mathrm{~m}^{2}$ \\
\hline 5 & 五家镇中心卫生院 & 哈尔滨市双城区五家镇 & 2008 & 38000 人 & $1600 \mathrm{~m}^{2}$ \\
\hline 6 & 新兴镇卫生院 & 哈尔滨市双城区新兴镇 & 2006 & 19800人 & $1000 \mathrm{~m}^{2}$ \\
\hline 7 & 幸福乡卫生院 & 哈尔滨市双城区幸福乡 & 2011 & 21000 人 & $800 \mathrm{~m}^{2}$ \\
\hline 8 & 东官镇卫生院 & 哈尔滨市双城区东官镇 & 2010 & 15263人 & $1520 \mathrm{~m}^{2}$ \\
\hline 9 & 青岭乡卫生院 & 哈尔滨市双城区青岭乡 & 2013 & 20000 人 & $700 \mathrm{~m}^{2}$ \\
\hline 10 & 牛家满族镇卫生院 & 五常市牛家满族镇 & 2009 & 32100 人 & $3100 \mathrm{~m}^{2}$ \\
\hline 11 & 周家镇中心卫生院 & 哈尔滨市双城区周家镇 & 2009 & 32236人 & $2500 \mathrm{~m}^{2}$ \\
\hline 12 & 天山口镇卫生院 & 内蒙古赤峰市 & 2009 & 32243 人 & $1280 \mathrm{~m}^{2}$ \\
\hline 13 & 旭光卫生所 & 哈尔滨市红旗乡 & 2006 & 14532人 & $1090 \mathrm{~m}^{2}$ \\
\hline
\end{tabular}

\section{1. 建筑运作体系方面}

笔者通过调研发现, 目前中国寒地乡镇医疗机构缺乏 系统的、专业的应灾建筑运作体系。

独立空间运作体系和协作运作体系是医疗机构应灾 建筑运作体系不可或缺的两方面。独立运作体系是指使医 疗机构在灾时能够独立的维持建筑正常运作的建筑运作 体系, 它能在灾时保证医疗机构自身的建筑安全; 协作运 作体系是指使医疗机构在灾时能够相互协作、合理分配和 利用医疗资源的建筑运作体系, 它能在灾时满足乡镇居民 激增的就医需求。

\subsection{1. 不具独立运作体系}

具备独立运作体系是寒地乡镇医疗机构的基本应灾 需求, 也是使乡镇医疗机构成为灾时人民庇护所的必要条 件。当极端气候灾害来临时, 有效的独立运作体系可以使 乡镇医疗机构能够在外部救援到来前独立的运作一定时 间, 在第一时间满足所辖区域病患的最基本就医需求。因 此, 可以说有效的独立运作体系是受灾群众的第一把保护 伞。

而在调研过程中笔者发现, 很多寒地乡镇医疗机构并 不具备独立运作体系。周家镇卫生院和牛家满族镇卫生院 都是由住宅建筑改造而来, 卫生院所使用的设施均为民用
设施, 不具备独立发电机、独立储水箱、独立的燃气和采 暖设施等独立运作体系的必要设施。当遭遇低温冷冻、雪 灾和大风等极端气候灾害时, 面对电力中断、水资源紧张 以及灾后激增的就诊需求, 不具独立运作体系的寒地乡镇 医疗机构将丧失大部分医疗服务能力, 无法有效的保障当 地人民的生命财产安全。

\subsection{2. 不具协作运作体系}

具备协作运作体系是寒地乡镇医疗机构的核心应灾 需求, 也是从根本上加强其应灾能力的有效办法。当极端 气候灾害来临时, 合理的协作运作体系可以使寒地乡镇医 疗机构能够实现医疗资源的最优分配，切实的增强乡镇区 域的应灾能力[7]。而在调研的过程中, 笔者通过对以红旗 镇卫生院院长为代表的寒地乡镇医疗机构职员的采访发 现, 目前寒地乡镇医疗机构缺乏应对极端气候灾害的行之 有效的协作运作体系。

从调研中获知, 目前乡镇居民的就医次序为“村卫生 室 $\rightarrow$ 一般卫生院（或中心卫生院）－县医院”。这是一种 以县医院为核心的“向心聚拢型”医疗资源分配模式 $[8]$; 而 当极端气候灾害来临时, 较为贫困、医疗条件较差的乡镇 区域才是受灾较为严重的地区, 这与目前的医疗资源分配 模式恰恰相反（如图1和图2）。

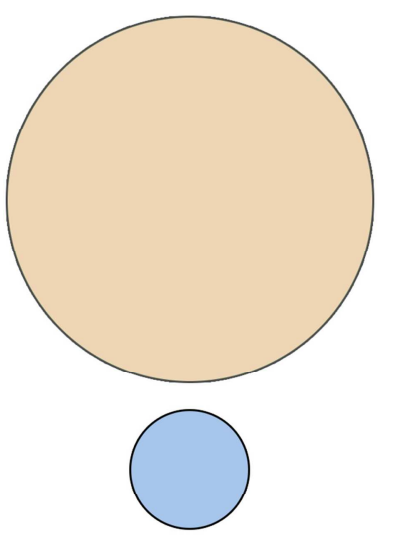

村卫生室

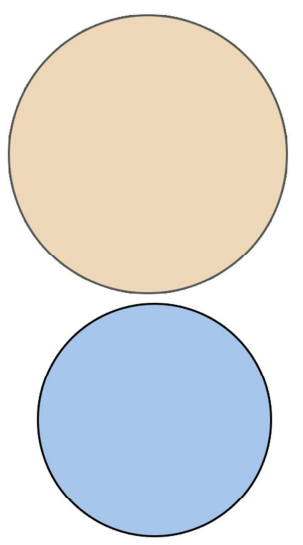

卫生院

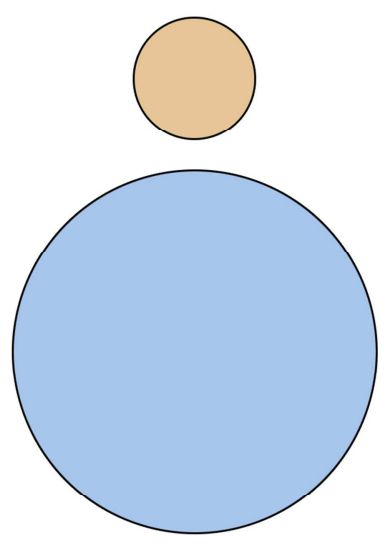

县医院

受灾可能性与受灾程度

医疗资源与医疗条件

图1 乡镇医疗机构医疗资源与受灾程度示意图。 


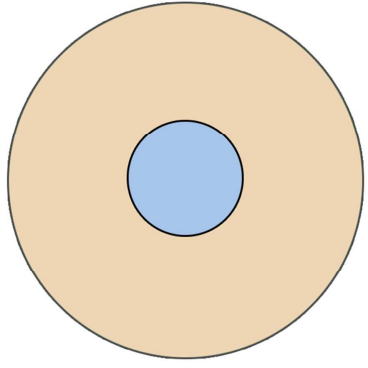

村卫生室:应灾医疗资源极短缺

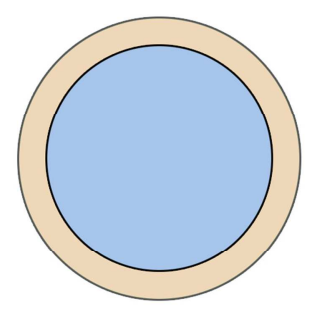

卫生院:应灾医疗资源较紧张

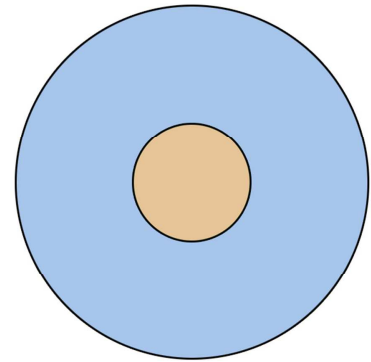

县医院:应灾医疗资源富足且溢出

受灾可能性与受灾程度

医疗资源与医疗条件

图2 乡镇医疗机构应灾医疗资源示意图。

医疗资源富足的区域受灾较轻微、医疗资源短缺的区 域受灾严重, 因此, 建立一个集“村卫生室、乡镇卫生院、 县医院”等乡镇医疗机构为整体的协作运作体系, 从而优 化各个单位医疗资源的灾时流动分配, 是提升寒地寒地乡 镇医疗机构应灾保障能力的关键办法。

\section{2. 建筑内部空间方面}

笔者通过调研发现, 当面临极端气候灾害时, 中国寒 地乡镇医疗机构的建筑内部缺乏足够的应灾空间。

这种建筑内部空间的不足表现在两个方面。一是面对 灾后激增的就诊需求, 寒地乡镇医疗机构缺乏足够的诊疗 空间, 即缺乏诊室与病房; 二是面对由极端气候灾害引起 的大规模爆发的呼吸系统、心血管系统和外科伤病时, 寒 地乡镇医疗机构缺乏针对特定疾病的诊疗空间, 即科室的 应灾适应性较差。

\subsection{1. 室内应灾空间不足}

具备足够数量的诊室和病房是寒地乡镇医疗机构建 筑内部空间的基本应灾需求。

通过调研笔者发现, 目前寒地寒地乡镇医疗机构内部 空间的设计只针对日常的就诊需求, 未曾考虑过灾时和灾 后等应急状态下激增的就诊需求。哈尔滨市红旗乡旭光卫 生所仅有两间诊室和两间病房, 四个房间使用面积总计不 足 $100 \mathrm{~m}^{2}$ 。据旭光卫生所的员工所述, 目前的诊疗空间可 以满足辖区居民的日常就诊需求, 但是面对恶劣天气所引 起的病情爆发, 有时病患人数能达到平常的 3-5倍, 目前 的诊疗空间等室内应灾空间远远不够。

\subsection{2. 科室应灾适应性不足}

具备应灾适应性较好的科室的寒地乡镇医疗机构能 够大幅的提高地区的灾时医疗服务效率。

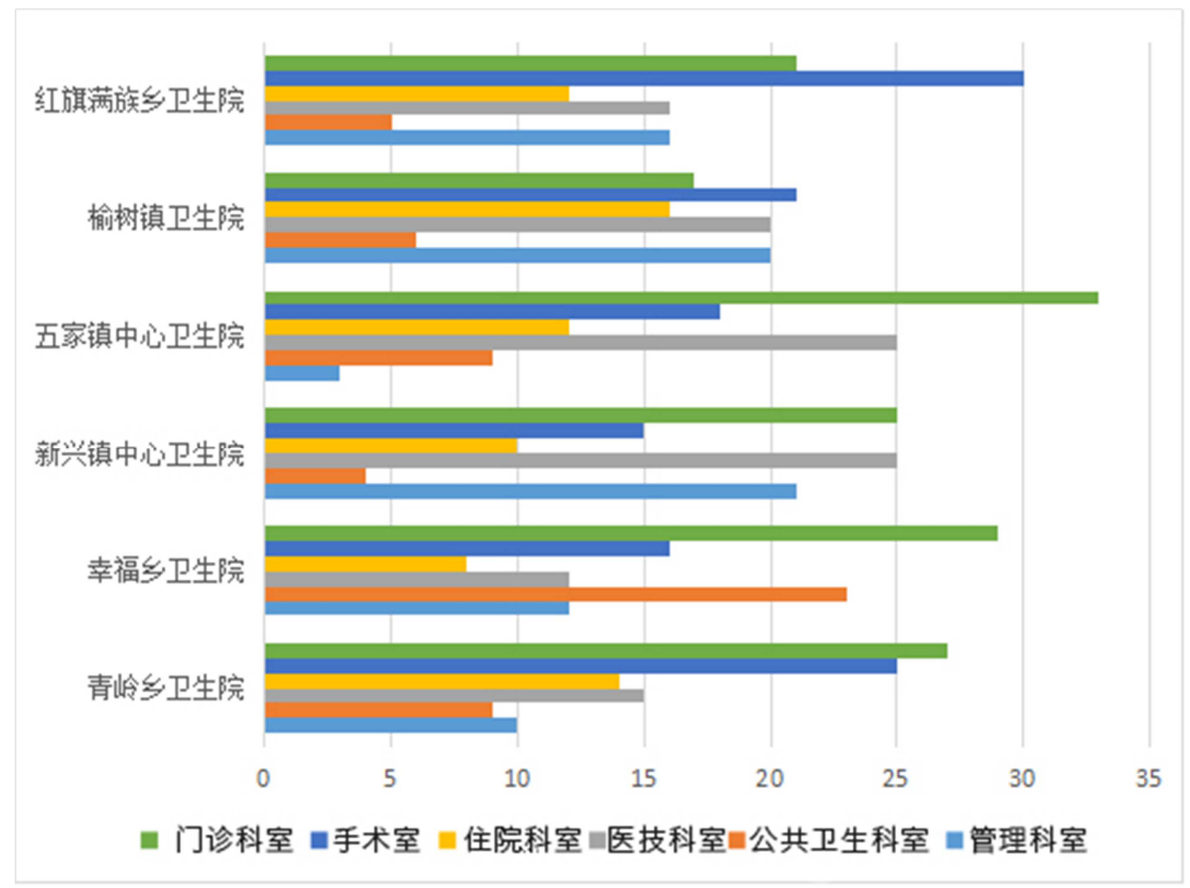

图3 寒地乡镇医疗机构内部功能配比图。 
在中国国家政策的引导和帮助下, 目前寒地乡镇医疗 机构科室的服务功能已经向多元化发展[9]。笔者重点调研 了以红旗满族乡卫生院、榆树镇卫生院、五家镇中心卫生 院、新兴镇中心卫生院、幸福乡卫生院、青岭乡卫生院为 代表寒地乡镇医疗机构, 发现目前寒地乡镇医疗机构的基 本都已包含：公共卫生科室、门诊科室、住院科室、医技 科室和管理科室（如图3和图4）。这些多元化的科室全方 位的保障了乡镇居民的健康与安全。但是当极端气候灾害 来临时, 往往会出现急诊科、内科、外科、儿科等门诊科 室病患爆满, 而康复科、妇产科等门诊科室以及公共卫生 科室无人问津的现象。这说明乡镇医疗机构常态下的科室 功能布置无法满足灾时和灾后的特殊需求, 即科室的设置 缺乏应灾适应性。因此, 目前的寒地乡镇医疗机构需要一 种能够满足常态和应灾状态下就诊需求的乡镇医疗机构 内部空间设计方案。

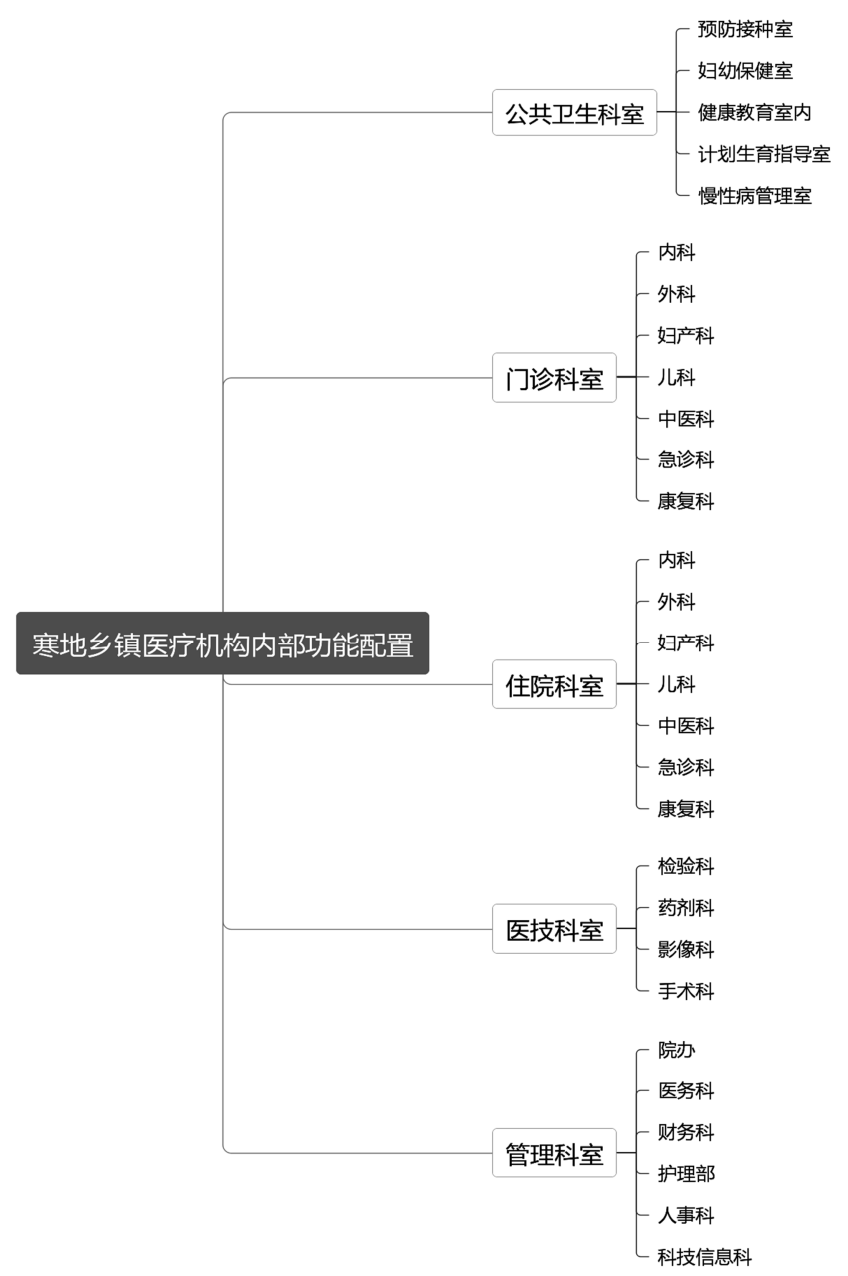

图4 寒地乡镇医疗机构内部功能配置图。

\section{4. 寒地乡镇医疗机构空间的应灾设计策略}

根据以上的调研结果, 笔者从建筑空间布局的角度出 发, 针对建筑运作体系和建筑内部空间两个方面提出寒地 乡镇医疗机构的应灾设计策略。

\section{1. 构建建筑应灾运作体系}

寒地乡镇医疗机构需要构建一种结合独立运作体系 和协作运作体系的新的建筑应灾运作体系。在这种建筑应 应灾运作体系中, 乡镇医疗机构应该既能够在灾时保证医 疗服务的正常运行、保障建筑的自身安全; 同时也需要与 周边的医疗机构建立灾时联系, 共享医疗资源, 实现有限 医疗资源的最大化利用。

第一, 建筑应灾运作体系要求寒地乡镇医疗机构设置 独立的供电设施、独立储水箱、足够的药剂储备、独立的 燃气和采暖设施等独立资源设施, 以保证在建筑在极端气 候灾害中可以独立的为居民提供稳定的医疗服务, 同时等 待外界的医疗援助。

另一方面, 建筑应灾运作体系要求“村卫生室、卫生 院、县医院”不同层级的寒地医疗机构能够在灾时形成紧 密的“医疗联合体”。受灾较轻、医疗资源丰富的机构向受 灾较重、医疗资源贫乏的机构输送溢出的医疗资源。由原 来的以县医院为核心的“向心聚拢型”医疗资源分配模式 变为一种“按需分配、共享资源”的医疗资源分配模式 (如 图5和图6）。

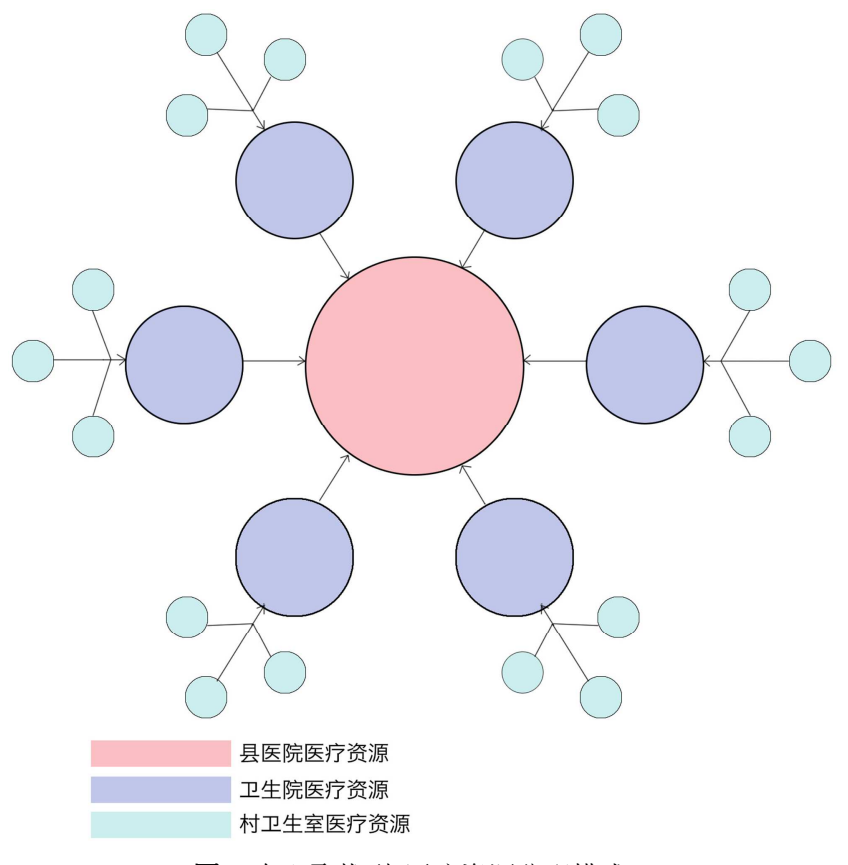

图5 “向心聚拢型”医疗资源分配模式。

通过以上两个方面, 完成建筑应灾运作体系的构建。 相较于目前寒地乡镇医疗机构的建筑运作体系, 在新的建 筑应灾运作体系下, 乡镇医疗机构本身的应灾能力更强、 医疗机构之间联系更加紧密。这样的建筑应灾运作体系不 仅保障了寒地乡镇医疗机构的建筑安全、还实现了有限资 源的合理利用, 从而加强整个地区的应灾抗灾能力。 


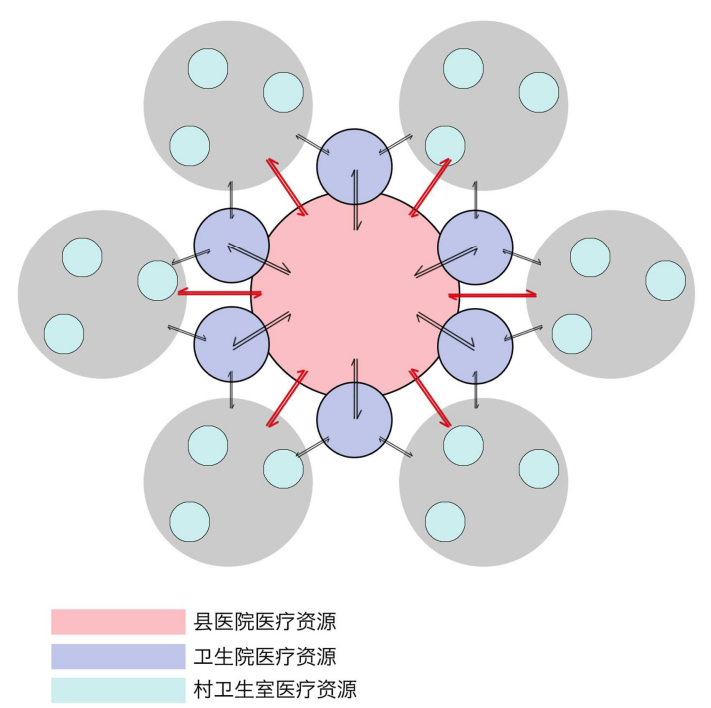

\section{2. 采用模块化和灾时功能转化设计对策}

寒地乡镇医疗机构宜采用模块化空间设计对策和灾 时功能转化设计对策来应对目前存在的“室内应灾空间不 足”、“科室应灾针对性较差”的建筑内部空间问题。

灾时功能转化设计对策, 是指当极端气候灾害发生时, 主动的转变寒地乡镇医疗机构部分房间的功能, 以满足灾 后特殊的就诊需求。它包含两个方面的内容: 第一, 将部 分公共卫生科室的房间功能转化为门诊科室和住院科室, 以解决灾时诊室和病房等室内应灾空间匮乏的问题 (如图 7）; 第二, 将部分妇产科、中医科、康复科的房间功能 转化为外科、内科、儿科和急诊科, 以应对极端气候灾害 后大面积爆发的呼吸系统疾病、心血管系统疾病以及摔伤、 骨折等外科伤病, 从而解决寒地乡镇医疗机构科室的应灾 适应性较差的问题（如图8）。

图6 “按需分配、共享资源”的医疗资源分配模式。

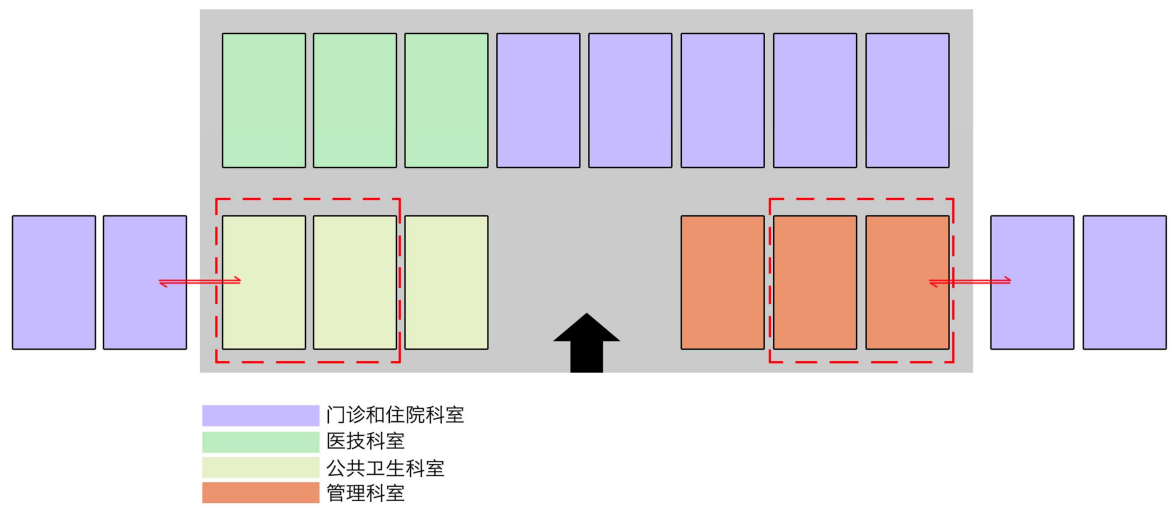

图7 灾时功能转化设计对策 (一) 示意图。

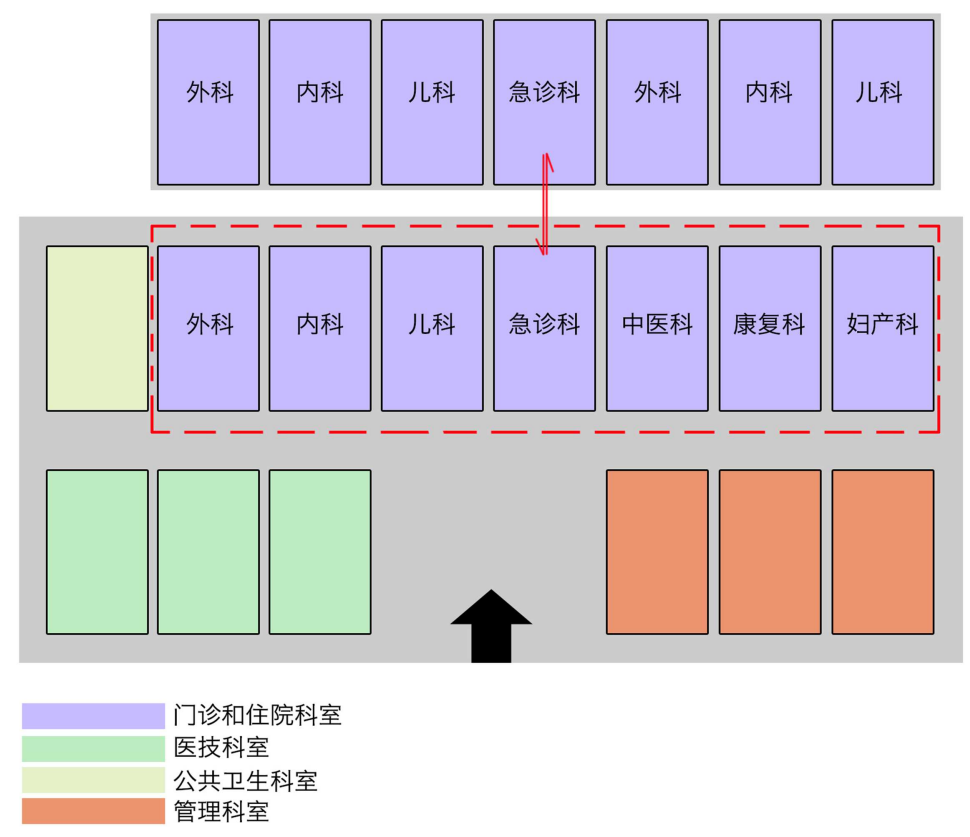

图8 灾时功能转化设计对策 (二) 示意图。

同一房间不一定能够转化为其他功能的房间, 而模块 化空间设计能使各个房间标准化、统一化、通用化，从而
保证灾时功能转化对策的顺利实施。因此, 采用模块化空 间设计对策是实现不同房间功能转化的前提条件。模块化 
空间设计是指将某一标准空间作为单元模块进行设计与 施工, 这种单元模块可以可以通过称重单元块堆叠, 或者 以承重骨架为支撑、将轻质单元块固定其上的两种方式实 现整体建筑的建设 [10]。将寒地乡镇医疗机构的门诊科室、 住院科室、公共卫生科室、管理科室的空间进行模块化设 计, 可以实现灾时不同房间快速的功能转化, 以应对极端 灾害爆发时居民特殊的就诊需求。

模块化的空间设计思路不应该只局限于改变现有的 内部空间。近年来, 模块化的医疗单元体在应灾方面的使 用逐渐成为热门话题。2009年, 美国的IK studio针对突发 性传染病的医疗隔离单元进行过设计和研究。2015 年, 在世界建筑师协会公共健康分会 (UIA-PHG) 组织的医疗 设施竞赛中, 亦针对传染病暴发的背景, 以预制模块化的 可移动医疗单元体的概念, 对未来医疗设施走向进行讨论 [10]。模块化的医疗单元体存在独立使用和临时组合两种 使用方式, 即作为医疗供应站或活动医疗单体独立使用。 独立的模块化的医疗单元体可以在应对极端气候灾害或 紧急医疗任务时, 为受灾的地区提供一个用于承接外部救 援医疗资源的载体。第一，模块化的医疗单元体可以在灾 时外接与原有的乡镇医疗机构建筑, 拓展建筑的医疗空间; 第二, 模块化的医疗单元体可以在灾时快速搭建, 在合适 的位置形成临时的医疗基地, 缓解重灾区的救援压力。

灾时功能转化设计对策是解决问题的核心举措; 模块 化的空间设计对策是实现灾时功能转化对策的必要前提 条件; 模块化的医疗单元体的独立使用和临时组合使用是 寒地乡镇医疗机构应灾设计的未来发展趋势。采用模块化 和灾时功能转化两种设计对策, 可以在灾时增加乡镇医疗 机构诊室和病房等室内应灾空间的的数量, 使诊疗空间具 有更好的应灾适应性, 切实的增强了建筑内部的应灾抗灾 能力。

\section{5. 结论}

本研究通过广泛和认真的调研, 基于寒地乡镇医疗机 构应对极端气候灾害的现状, 提出了集独立和协作建筑运 作系统于一体的建筑应灾体系构建思路, 以及以模块化和 灾时功能转化对策为基础的建筑内部空间应灾设计方案。 从建筑学的角度, 解决了寒地乡镇医疗机构“独立运作能 力差、协作能力差、室内应灾空间数量及适应性不足”的 问题, 实现了寒地乡镇医疗机构应灾空间的体系化和精准 化, 进一步保障了乡镇居民的公共健康与安全。为改变寒
地乡镇医疗机构布局不够充分靠前、应对突发灾害反应时 间过长的现状做出有效的努力。

\section{致谢}

衷心的感谢哈尔滨工业大学白小鹏教授对本研究的 悉心指导与点拨; 十分感谢哈尔滨工业大学张姗姗教授亲 自指导制定调研计划并组织人员实践调研, 为笔者后期的 研究及成果的得出提供了莫大的帮助; 感谢哈尔滨工业大 学公共建筑与环境设计研究所提供的宝贵的调研资料; 最 后同样十分感谢ICPHMS2018组委会对本研究的认可与肯 定。

\section{参考文献}

[1] 李燎原.严寒地区可移动应急医疗空间设计[D].哈尔滨:哈 尔滨工业大学, 2017: 1。

[2] 刘雅倩, 郑勇, 廖菁, 李芳平, 蔡力.小康型乡镇卫生院建 设标准初探[J].实用医院临床杂志, 2011, 2011(06): 183-188。

[3] 杨萍.近四十年中国极端温度和极端降水事件的群发性研 究[D].兰州:兰州大学, 2009: 1。

[4] 李燎原.严寒地区可移动应急医疗空间设计[D]. 哈尔滨: 哈 尔滨工业大学, 2017: 1。

[5]王程浩. 寒地村镇医疗卫生设施设计策略研究[D]. 哈尔滨: 哈尔滨工业大学, 2017：20。

[6] 马玉琴, 孙金海, 李婷, 张鹭鹭.“城乡一体化”模式下乡镇 卫生院的功能定位与思考 [J]. 中国初级卫生保健, 2008, 2008(01): 7-9。

[7] 王程浩.寒地村镇医疗卫生设施设计策略研究[D].哈尔滨: 哈尔滨工业大学, 2017：52。

[8] 王苗苗. 严寒地区乡镇卫生院建筑综合评价研究[D]. 哈尔滨: 哈尔滨工业大学, 2017: 2。

[9] 刘雅倩, 郑勇, 廖菁, 李芳平, 蔡力.小康型乡镇卫生院科 室标准设置初探 [J]. 实用医院临床杂志, 2011, 2011(06): 191-194。

[10] 张姗姗, 朱丽玮.医院建筑装配式建设趋势与空间模块化实 现[J].城市建筑, 2017，2017(13): 30-32。 